\title{
Office hysteroscopy: a review
}

\section{Vijayalakshmi Shanbhag*, Nilaj Bagde}

Department of obstetrics and gynecology, AIIMS, Raipur, Chhattisgarh, India

Received: 15 November 2021

Accepted: 03 December 2021

\section{*Correspondence:}

Dr. Vijayalakshmi Shanbhag,

E-mail: vijayalakshmi.shanbhag.vs@gmail.com

Copyright: () the author(s), publisher and licensee Medip Academy. This is an open-access article distributed under the terms of the Creative Commons Attribution Non-Commercial License, which permits unrestricted non-commercial use, distribution, and reproduction in any medium, provided the original work is properly cited.

\begin{abstract}
With the invention of new techniques and modalities "see and treat" has become the norm of management now a days. Diagnostic hysteroscopy combined with histological examination of an endometrial biopsy is considered the 'gold standard' in the diagnosis of intrauterine abnormalities. The importance of office hysteroscopy lies in the fact that there is no need of any anesthesia and after the procedure the patient can return into his routine activity only with the minimal aid of NSAIDs. Two different types of hysteroscopes are used worldwide: flexible or rigid, which are made in different sizes. Optic miniaturization has been one of the greatest technological advancements in the field of hysteroscopy, both for rod-lens and fiberoptic scopes. The main concerns in office hysteroscopy are the need for necessary expertise, pain management and management of the complications in the office setting and the high cost of the equipment needed for the procedure. But office hysteroscopy has already demonstrated good correlation of findings compared with inpatient hysteroscopy, providing distinct advantages such as reduced anesthesia risks, enhanced time and cost-effectiveness, and faster recovery with less time away from work and home.
\end{abstract}

Keywords: Office hysteroscopy, Mini-hysteroscope, Fibreoptic scope, Intrauterine abnormalities

\section{INTRODUCTION}

Technical and technological advancements in gynecology have continuously revolution our everyday life. Medical knowledge is ever changing. With the invention of new techniques and modalities "see and treat" has become the norm of management now a days. Diagnostic imaging procedures and surgical endoscopy are among the fastest developing medical procedures of the century. Hysteroscopy, a gold standard in the evaluation and treatment of intrauterine pathology was considered an invasive procedure with a long learning curve but with the revolutionary advances taking place in the field of digital imaging and miniaturization of high-definition endoscopes have made hysteroscopy a simple, safe and well tolerated office procedure. Office hysteroscopy and hysteroscopic surgery has become an integral component of modern gynecological care.

Hysteroscopy is a powerful diagnostic tool for visualizing the cervical canal and uterine cavity, with better results than dilatation and curettage. ${ }^{1}$ Although laparoscopy has doubtlessly expanded the range of options available for gaining access to the abdominal cavity, it is hysteroscopy that for the first time ever helped to 'elucidate' an obscure and isolated region which has not been explored in any direct sense. Hysteroscopy has the advantage of directly visualizing the uterine cavity and endometrium allowing biopsy to be taken immediately from the suspected abnormality under direct vision but it does not give any information regarding adnexa and myometrium. ${ }^{2}$

\section{BACKGROUND}

Diagnostic hysteroscopy combined with histological examination of an endometrial biopsy is considered the 'gold standard' in the diagnosis of intrauterine abnormalities. ${ }^{3}$ Hysteroscopy has achieved the goal of becoming an outpatient diagnostic and therapeutic procedure that is easily done even by beginners, confining resectoscopic procedures for selected cases to be treated by operators with necessary experience. Diagnostic 
hysteroscopy is the criterion standard examination for pathologic conditions that might have repercussions on the uterus such as abnormal uterine bleeding, endometrial hypertrophy, and carcinoma of the endometrium. ${ }^{4}$

In recent years, an innovative hysteroscopic tissue removal system (HTRs) based on mechanical removal of intrauterine lesions has been developed. A systematic review and meta-analysis showed that women treated with HTRs for endometrial polyps have a shorter procedure time than those treated with loop or bipolar electrode resection in an operating room or in an office setting. ${ }^{5}$ Gkrozou et al in a meta-analysis over 9000 patients evaluating the accuracy of hysteroscopy in diagnosing endometrial cancer, hyperplasia, polyps and submucous myomas, found a high diagnostic accuracy for endometrial cancer diagnosis (estimated sensitivity $82.6 \%$ and specificity $99.7 \%)^{6}$

The importance of office hysteroscopy lies in the fact that there is no need of any anesthesia and after the procedure the patient can return into his routine activity only with the minimal aid of NSAIDs. With the addition of some operative procedures done using an office hysteroscope the outlook of the patient management is changing from the days with prolonged hospitalization to day care approach.

In this review we provide an insight into the various aspects of office hysteroscopy, its indications, equipment, and procedures and also review strategies for management of pain and/or complications that may arise within an office-based practice.

The main concerns in office hysteroscopy are the need for necessary expertise, pain management and management of the complications in the office setting and the high cost of the equipment needed for the procedure. But office hysteroscopy has already demonstrated good correlation of findings compared with inpatient hysteroscopy, providing distinct advantages such as reduced anesthesia risks, enhanced time- and cost-effectiveness, and faster recovery with less time away from work and home. ${ }^{7}$

Common office procedures include diagnostic hysteroscopy, endometrial biopsy with direct hysteroscopic visualization, endometrial polypectomy, lysis of intrauterine adhesions, resection of small submucous leiomyomas, placement of permanent contraceptive implants, removal of foreign objects or dislodged IUDs, removal of retained products of conception, and uterine metroplasty. ${ }^{8}$

\section{Aims}

This article aims to provide a comprehensive information on office hysteroscopy and its relevance in the modern era. Although it is still evolving and continuous scientific inventions in the field of hysterolaparoscopy are taking place, this article aims to enlighten the readers with updated reviews on the use of hysteroscopy in the office setting so that the blind procedures in treatment of various intrauterine pathologies can be changed to the evidence based see and treat approach of hysteroscopy.

\section{LITERATURE REVIEW}

This review article included medical articles about office operative hysteroscopy published in English and identified via a search of MEDLINE, EMBASE, and the Cochrane database of systematic reviews. All cross-references were hand-searched, as were relevant conference abstracts. All types of studies were selected. Studies in which surgical and operative procedures were performed using minihysteroscopes $(<5 \mathrm{~mm})$ in an office setting and without the need of cervical dilatation were included.

\section{CONSIDERATIONS IN OFFICE HYSTEROSCOPY}

Over the past 40 years, the higher diagnostic accuracy related to the possibility of direct endoscopic vision of the distended uterine cavity together with continuous and rapid advances in technologies and techniques, have opened up new horizons for hysteroscopic modalities, which today are considered the gold standard of diagnostic and therapeutic options in the management of intrauterine pathologies, and, more recently, of those seen in the cervix and vagina.

The setting of office hysteroscopy should be in a comfortable environment for the patient as the patient will be conscious during the procedure. The medical staff and the team should explain the patient about the procedure and the 'See and treat 'approach involved in it. During the procedure the nursing staff should provide emotional support to the patient and instill confidence in her.

Two different types of hysteroscopes are used worldwide: flexible or rigid, which are made in different sizes. The standard rigid hysteroscopes, used for decades, had a diameter greater than $5 \mathrm{~mm}$, with a $4-\mathrm{mm}$ telescope. Over the last few years, smaller-diameter hysteroscopes have been introduced, reflecting the trend toward less-invasive diagnostic and operative procedures in all fields of medicine.

Flexible hysteroscopy is well suited for endometrial evaluation. The advantages of office flexible hysteroscopic visualization include excellent patient acceptance and comfort, office evaluation, direct visualization of the endometrium and endocervix, the ability to detect minute focal endometrial pathology, the ability to perform directed endometrial biopsies (with some hysteroscopes), and the ability to lyse filmy adhesions with the distal tip of the flexible hysteroscope. ${ }^{9}$

In outpatient hysteroscopy, saline solution and $\mathrm{CO}_{2}$ are the most common media for intracavitary distention. Although $\mathrm{CO}_{2}$ is generally well tolerated, uterine distension with saline solution is preferable. Distension with fluid is a cost- 
effective approach associated with less patient discomfort and clearer hysteroscopic vision in the occurrence of intrauterine bleeding. ${ }^{10}$

\section{SPECIFIC INDICATIONS FOR HYSTEROSCOPY}

Currently, appropriate equipment, proper training and knowledge are sufficient to practice safe in office operative hysteroscopy. In the present section, we review ambulatory setting treatments of common endo-uterine diseases.

\section{Abnormal uterine bleeding}

AUB and its sub group, heavy menstrual bleeding (HMB), are common conditions affecting $14-25 \%$ of women of reproductive age. and may have a significant impact on their physical, social, emotional and material quality of life. ${ }^{11}$

Once bleeding is defined as being abnormal, the acronym PALM-COEIN is now being increasingly used for categorising causes: polyp, adenomyosis, leiomyoma, malignancy (and hyperplasia), coagulopathy, ovulatory disorders, endometrial, iatrogenic and not otherwise classified. The 'PALM' is assessed visually (imaging and histopathology) and the 'COEIN' are non-structural. ${ }^{12}$

Abnormal bleeding continues to be the most common indication for performing office hysteroscopy. Numerous studies have demonstrated the success rates of diagnostic hysteroscopy in the office setting to be as high as $98.4 \% .{ }^{13}$ Office hysteroscopy is most beneficial in patients who will not be taken to the OR if the results of office hysteroscopy are negative for pathology. Minimal to no pain has proved to be a benefit of using a thin and flexible hysteroscope for office diagnostic hysteroscopy.

\section{Hysteroscopy for perimenopausal and/or postmenopausal bleeding}

The mean age of menopause in women is between 50 and 52 years (51.3 years.). ${ }^{14}$ The 2-8 years before menopause, most women present anovulatory cycles with long proliferative phases and reduced numbers of follicles. ${ }^{15}$ Abnormal uterine bleeding during the perimenopausal and postmenopausal periods is common and a frequent cause for concern. There is a need for accurate diagnosis of endometrial pathology and a thorough evaluation of the uterine cavity in order to exclude endometrial neoplasia, a condition occurring with increasing incidence and possessing potentially serious consequences. AUB in perimenopausal and postmenopausal years is managed traditionally by dilatation and curettage, a method with lower sensitivity in the detection of focal endometrial lesions compared to hysteroscopy. There is an increased incidence of endometrial pathology diagnoses in women who present AUB while taking Hormone replacement therapy. Identification of the exact endometrial pathology by hysteroscopy and endometrial biopsy and the subsequent treatment of patients may avoid the need for discontinuation of Hormone replacement Therapy, especially in the first few months of the therapy when most episodes of AUB usually occur. ${ }^{16,17}$

\section{Hysteroscopy for women with implantation or fertility problems}

One of the basic steps of the infertility workup is to assess the shape and regularity of the uterine cavity. Historically, and still today as it turns out, the HSG has been the most commonly used test for this purpose. Hysteroscopy has been proved to be the definite method for evaluation of the uterine cavity and diagnosis of associated abnormalities. Office hysteroscopy is only recommended by the WHO when clinical or complementary exams (ultrasound, HSG) suggest intrauterine abnormality or after in vitro fertilization (IVF) failure. ${ }^{18}$ Several studies have demonstrated that once the uterine cavity has to be investigated as part of the infertility workup, hysteroscopy is much more accurate than other diagnostic methods, mainly HSG. ${ }^{19}$

\section{Hysteroscopy for the evaluation of recurrent pregnancy loss}

Recurrent pregnancy loss (RPL), also referred to as recurrent miscarriage or habitual abortion, is historically defined as 3 consecutive pregnancy losses prior to 20 weeks from the last menstrual period. Epidemiologic studies have revealed that $1 \%$ to $2 \%$ of women experience recurrent pregnancy loss. ${ }^{20}$ Anatomic abnormalities account for $10 \%$ to $15 \%$ of cases of RPL and are generally thought to cause miscarriage by interrupting the vasculature of the endometrium, prompting abnormal and inadequate placentation. The uterine septum is the congenital uterine anomaly most closely linked to RPL, with as much as a $76 \%$ risk of spontaneous pregnancy loss among affected patients. ${ }^{21}$ Hysteroscopic resection of intrauterine adhesions and intrauterine septa are indicated if these abnormalities are identified. Patients undergoing successful hysteroscopic septum resection seem to enjoy near normal pregnancy outcomes, with term delivery rates of approximately $75 \%$ and live birth rates approximating $85 \% .^{22}$ Myomectomy should be considered in cases of submucosal fibroids or any type fibroids larger than $5 \mathrm{~cm}$. Resection has been shown to significantly improve live birth rates from $57 \%$ to $93 \% .^{23}$

\section{Hysteroscopy for intrauterine adhesions or synechiae}

Asherman's syndrome is a rare, acquired, gynaecological disorder of the uterus. It is characterized by the bonding of scar tissue that lines the walls of the uterus, which decreases the volume of the uterine cavity. The impact of the Asherman syndrome on pregnancy is well documented with a high rate of infertility, miscarriage, poor implantation following in vitro fertilization and abnormal placentation. $^{24}$ 
Office hysteroscopy serves good in postoperative followup to check the de novo intrauterine adhesions (IUAs) formation. A study found that the de novo IUAs formation after septal incision, adhesiolysis, and myomectomy were $88 \%, 76 \%$, and $40 \%$, respectively; in contrast to none of polypectomy. ${ }^{25}$ Hysteroscopic surgery has revolutionized the treatment of intrauterine adhesion and it is the established gold standard technique. When the lesions are filmy, the tip of the hysteroscope and uterine distension may be enough to break down the adhesions. ${ }^{26}$ Any central and filmy adhesions should be separated initially in order to allow adequate distension of the uterine cavity. Dense and lateral adhesions should be treated at the end, bearing in mind the greater risk of uterine perforation and bleeding. ${ }^{27}$

\section{Office-based hysteroscopic metroplasty}

The introduction of operative hysteroscopy has greatly simplified the treatment of special categories of uterine malformations such as septate uterus. However, some gynecologists have performed metroplasty in the office setting using scissors in cases of limited small septae. ${ }^{28,29}$ Bettocchi et al correctly evaluated the uterine anatomy in $93.1 \%$ of cases using only the 3 diagnostic criteria. These authors observed that the uterine septum, because of its fibrotic nature, is whitish, without vessels, and not sensory innervated. In contrast, the wall of a bicornuate uterus, because of its muscle fibers, is pinkish, and rich in vessels and sensitive terminations. ${ }^{30}$

\section{Advantages of mini-hysteroscope}

Optic miniaturization has been one of the greatest technological advancements in the field of hysteroscopy, both for rod-lens and fiberoptic scopes. This has significantly improved patients' compliance to the procedure, contributing to the performance of hysteroscopy as an office procedure. In a study by Cicinelli et al it was found that Pain and vasovagal reactions were significantly lower with the mini-hysteroscope compared with the standard one $(0.10 \pm 0.34$ vs $1.09 \pm 0.53$ and $2.25 \%$ vs $17.12 \%$, respectively, on a scale where $0=$ no pain and $3=$ intolerable pain). ${ }^{31}$ Reduced pain and greater safety of hysteroscopy performed with mini-hysteroscopes has been confirmed by results of other studies by Rull et al, De Angelis et al and Campo et al as well. ${ }^{32-34}$

\section{CONCLUSION}

Office hysteroscopy is a safe and effective technique, not requiring the use of operation theatre, hospital admission and general or local anesthesia thus reducing the morbidity in the patients due to nosocomial infection and psychological and economic burden of hospital admission. It provides for an excellent diagnosing tool by providing a peek into the otherwise inaccessible uterine cavity and also allows for minor office operative procedures in the same sitting thus avoiding multiple hospital visits. The controversies were raised in the past about the hysteroscopy were not for the efficacy of hysteroscopy per se but from its relatively costly and invasive nature in comparison to other noninvasive diagnostic modalities for intrauterine pathologies like imaging modalities i. e., TVS. But the application of office hysteroscopy in conscious patients with such minimal invasiveness and without the inconvenience of anesthesia and need for operation room has been a great advance in the field of intrauterine pathologies. Patient safety is at the very core of risk management and is the first and foremost domain of healthcare. We are of the opinion that the office hysteroscopy has all the features to be considered as the gold standard for diagnosis and treatment of intrauterine pathologies.

\section{Funding: No funding sources \\ Conflict of interest: None declared \\ Ethical approval: Not required}

\section{REFERENCES}

1. Loffer FD. Hysteroscopy with selective endometrial sampling compared with $\mathrm{D}$ and $\mathrm{C}$ for abnormal uterine bleeding: The value of a negative hysteroscopic view. Obstet Gynecol. 1989;73:16-20.

2. Cepn ÂI, Ocal P, Erkan S. Comparison of transvaginal sonography, saline infusion sonography and hysteroscopy in the evaluation of uterine cavity pathologies. Aust N Z J Obstet Gynaecol. 2005;45:305.

3. Tahir MM, Bigrigg MA, Browning JJ. A randomized controlled trial comparing transvaginal ultrasound, outpatient hysteroscopy and endometrial biopsy with inpatient hysteroscopy and curettage. $\mathrm{Br} \mathrm{J}$ Obstet Gynaecol. 1999;106:1259-64.

4. Chang CC. Efficacy of office diagnostic hysteronfibroscopy. J Minim Invasive Gynecol. 2007;14:1725.

5. Noventa M, Ancona E, Quaranta M. Intrauterine Morcellator devices: The icon of hysteroscopic future or merely a marketing image? A systematic review regarding safety, efficacy, advantages, and contraindications. Reprod Sci. 2015;22:1289-96.

6. Gkrozou F, Dimakopoulos G, Vrekoussis T, Lavasidis L, Koutlas A, Navrozoglou I. Hysteroscopy in women with abnormal uterine bleeding: a meta-analysis on four major endometrial pathologies. Arch Gynecol Obstet. 2015;291(6):1347-54.

7. Bettocchi S, Nappi L, Ceci O, Selvaggi L. Office hysteroscopy. Obstet Gynecol Clin North Am. 2004;31(3):641-54.

8. Di Spiezio Sardo A, Bettocchi S, Spinelli M. Review of new office-based hysteroscopic procedures 20032009. J Minim Invasive Gynecol. 2010;17:436-48.

9. Nagele F, O'Connor H, Davies A. 2500 Outpatient diagnostic hysteroscopies. Obstet Gynecol. 1996;88(1):87-92.

10. Campo R, Santangelo F, Gordts S, Di Cesare C, Van Kerr ebroeck H, De Angelis MC et al. Outpatient 
hysteroscopy. Facts Views Vis Obgyn. 2018;10(3):115-22.

11. Fraser IS, Langham S, Uhl-Hochgraeber K. Healthrelated quality of life and economic burden of abnormal uterine bleeding. Expert Rev Obstet Gynecol. 2009;4:179-89.

12. Munro MG, Critchley HO, Fraser IS. FIGO Working Group on Menstrual Disorders. FIGO classification of causes of abnormal uterine bleeding. Int J Gynaecol Obstet. 2011;113:1-2.

13. Ghaly S, De Abreu Lourenco R, Abbott JA. Audit of endometrial biopsy at outpatient hysteroscopy. Aust N Z J Obstet Gynaecol. 2008;48(2):202-6.

14. McKinlay SM, Brambilla DJ, Posner JG. The normal menopause transition. Maturitas. 1992;14:103.

15. Treolar AE, Boynton RE, Borghild GB, Brown BW. Variation of the human menstrual cycle through reproductive life. Int J Fertil. 1967;12:77.

16. Hahn RG, Nachtigal RD, Davies TC. Compliance difficulties with progestin supplemented replacement therapy. J Fam Pract. 1984;18:411-4.

17. Nachtigall LE. Enhancing patient compliance with hormone replacement therapy at menopause. Obstet Gynecol. 1990;75(1):77-80.

18. De Sa Rosa e de Silva AC, Rosa e Silva JC, Candido dos Reis FJ, Nogueira AA, Ferriani RA. Routine office hysteroscopy in the investigation of infertile couples before assisted reproduction. J Reproduct Med Obstetr Gynecol. 2005;50(7):501-6.

19. Shushan A, Rojansky N. Should hysteroscopy be a part of the basic infertility workup? Hum Reprod. 1999;14(8):1923-4.

20. Stephenson MD. Frequency of factors associated with habitual abortion in 197 couples. Fertil Steril. 1996;66:24-9.

21. Lin PC. Reproductive outcomes in women with uterine anomalies. J Womens Health. 2004;13:33-9.

22. Grimbizis GF, Camus M, Tarlatzis BC. Clinical implications of uterine malformations and hysteroscopic treatment results. Hum Reprod Update. 2001;7:161-74.

23. Bajekal N, Li TC. Fibroids, infertility and pregnancy wastage. Hum Reprod Update. 2000;6:614-20.
24. Yu D, Wong YM, Cheong Y, Xia E, Li TC. Asherman syndrome-one century later. Fertil Steril. 2008;11:759-79.

25. Yang JH, Chen MJ, Chen CD, Chen SU, Ho HN, Yang YS. Optimal waiting period for subsequent fertility treatment after various hysteroscopic surgeries. Fertil Steril. 2013;99:2092e2096-e3.

26. Sugimoto O. Diagnostic and therapeutic hysteroscopy for traumatic intrauterine adhesions. Am J Obstet Gynecol. 1978;11:539-47.

27. Deans R, Abbott J. Review of intrauterine adhesions. J Minim Invasive Gynecol. 2010;11:555-69.

28. Valle RF. Hysteroscopic treatment of partial and complete uterine septum. Int J Fertil. 1996;41:310-15.

29. Grimbizis G, Camus M, Clasen K, Tournaye H, De Munck L, Devroey P. Hysteroscopic septum resection in patients with recurrent abortions or infertility. Hum Reprod. 1998;13:1188-93.

30. Bettocchi S, Ceci O, Nappi L, Pontrelli G, Pinto L, Vicino M. Office hysteroscopic metroplasty: three "diagnostic criteria" to differentiate between septate and bicornuate uteri. J Minim Invasive Gynecol. 2007; 14:324-8.

31. Cicinelli E, Parisi C, Galantino P, Pinto V, Barba B, Schonauer S. Reliability, feasibility, and safety of mini-hysteroscopy with a vaginoscopic approach: experience with 6,000 cases. Fertil Steril. 2003;80:199-202.

32. Rullo S, Sorrenti G, Marziali M, Ermini B, Sesti F, Piccione E. Office hysteroscopy: comparison of 2.7and 4-mm hysteroscopes for acceptability, feasibility and diagnostic accuracy. J Reprod Med. 2005;50:458.

33. De Angelis C, Santoro G, Re ME, Nofroni I. Office hysteroscopy and compliance: mini-hysteroscopy versus traditional hysteroscopy in a randomized trial. Hum Reprod. 2003;18:2441-5.

34. Campo R, Molinas CR, Rombauts L. Prospective multicenter randomized controlled trial to evaluate factors influencing the success rate of office diagnostic hysteroscopy. Hum Reprod. 2005;20:25863.

Cite this article as: Shanbhag V, Bagde N. Office hysteroscopy: a review. Int J Reprod Contracept Obstet Gynecol 2022;11:287-91. 